\title{
Alcohol and other drug use in Michelin-starred kitchen brigades
}

\author{
Charalampos Giousmpasoglou ${ }^{\mathrm{a}^{*}}$, Lorraine Brown $^{\mathrm{b}}, \mathrm{Joh}_{\mathrm{C}}$ Cooper $^{\mathrm{c}}$ \\ $\mathrm{a}^{*}$ Corresponding author: Bournemouth University, Department of Tourism \& Hospitality, Talbot Campus, \\ Dorset House, BH12 5BB, Telephone: +44 (0) 1202 965265; E-mail: cgiousmpasoglou@ bournemouth.ac.uk \\ ${ }^{\mathrm{b}}$ Bournemouth University, Department of Tourism \& Hospitality, Talbot Campus, Dorset House, BH12 5BB \\ Telephone: +44 (0) 1202 961889; E-mail: lbrown@bournemouth.ac.uk \\ ${ }^{c}$ University of Strathclyde, Business School, 199 Cathedral Street, Glasgow G4 0QU \\ Telephone: +44 (0) 7831 838832; E-mail: john.cooper90@btopenworld.com
}

\begin{abstract}
This paper aims to explore chefs' experiences of the use of alcohol and other drugs (AOD) in Michelin-starred restaurants in Britain and Ireland. In total, 54 Head Chefs were interviewed in this study, which found AOD use to be part of their occupational culture. The work context plays a key role in this phenomenon in that harsh working conditions (such as heat, stress and long hours) provide fertile ground for AOD use as a means of self-medication and as a coping strategy. This study observes a normalisation of drinking to unwind. Even if this practice is detrimental to health, it is the coping mechanism used by chefs to deal with the stresses associated with the high end kitchen environment. Based on the findings of this research, it is argued that despite the industry's efforts to eliminate this phenomenon, AOD use is part of everyday life in high-end commercial kitchens.
\end{abstract}

Key Words: Hospitality; Chefs; Alcohol; Substance use; Britain and Ireland.

\section{Introduction}

Popular interest in chefs has grown considerably over the past two decades, as illustrated in increasing media coverage of Michelin-starred and celebrity chefs (Pizam, 2016) and the flourishing trend of biographies and other written accounts of both high-profile chefs and kitchen life (see Bourdain, 2000, 2010; Chelminski, 2006; Ramsay, 2006). The explosion of interest in cookery has led a number of chefs to gain celebrity status - a phenomenon also reinforced by media diversification which significantly increased their exposure across various media forms (Ashley et al., 2004; Wood, 2000). It is argued that the world of haute cuisine chefs was hidden until the emergence of the phenomenon of the celebrity chef and their open kitchens (Palmer et al., 2010), which revealed the previously secret 'backstage' (Goffman, 1959) of professional cooking. 'Haute cuisine' refers to the high-end of professional cooking, whilst being generally associated with critical acclaim, as embodied in the institution of the Michelin Guide and its star rating system (Surlemont and Johnson, 2005). Although haute cuisine implies a particular style of French cooking, the term is nowadays used in reference to gastronomic 
excellence, regardless of nationality (Ottenbacher and Harrington, 2007; Stierand and Dörfler, 2012). Although a marginal and elite segment of the restaurant industry, 'with less than 0.5 per cent in volume', the haute cuisine sector plays a key role in 'trend setting, image building and in setting standards for the industry as a whole' (Surlemont and Johnson 2005, p.578). It is for this reason that the focus of this research is on elite chefs.

Notwithstanding the growing media coverage of kitchens and chefs, the public is perhaps less aware of the toll cooking in a commercial kitchen takes on its chefs, particularly at the high end. This paper aims to shed light on what could be called the 'dark side' of fine dining restaurants by exploring the use of alcohol and drugs in Michelin-starred kitchen brigades in Great Britain and Ireland. Despite the existence of several empirical studies on alcohol and other drug (AOD) use in various occupational groups in the hospitality context (Belhassen and Shani, 2012; Pizam, 2010), little research has been carried out on the role of AOD use in the working life of chefs. According to Anderson (1998), the term substance abuse is commonly used to refer to an overindulgence and/or dependence on a substance, including alcohol, stimulants such as crack, cocaine, methamphetamine, hallucinogens, marijuana, and opioids. Substance abuse also includes the misuse of prescription medications obtained illegally, such as morphine derivatives (codeine, methadone etc.), and depressants (barbiturates, benzodiazepines etc.). It must be noted that not all patterns of use discussed in this paper necessarily fit the above definition. Therefore the authors prefer the term AOD 'use' instead of 'abuse' on the grounds that it describes patterns of alcohol and drug use that may, or may not, be abusive. For example, having one or two drinks of alcohol after work to wind down is not 'abuse' as alcohol is a central nervous system (CNS) depressant that has an initial relaxing effect, and it is commonly used for this effect. It only becomes 'abuse' if these one or two drinks lead to intoxication or if the person becomes dependent on alcohol as the only way to wind down (Jackson and Sartor, 2016).

The key research question that informed our study is as follows: "what is the relationship between AOD use, job characteristics and chefs' occupational culture in Michelin-starred kitchen brigades?"

\section{Literature Review: alcohol and other drug use in commercial kitchens}

\subsection{An overview of previous research on kitchen work}

Before reviewing the literature on AOD use in kitchens, a brief synopsis of existing research on the life of kitchen and restaurant workers will be offered. A number of empirical studies regarding work in commercial kitchens, mainly focused on the US and UK context, can be found in the literature. These include, in the UK: Bowey (1976); Saunders (1981a, 1981b), and in the US: Guyette (1981); Ferguson 
and Zukin (1998); Peterson and Birg (1988). However, it must be noted that these studies are not focused entirely on the chef's occupational context. In the UK context, the now dated research of Chivers (1972, 1973) is dedicated entirely to the occupation of chefs and cooks. In the US context, the work of Fine (see 1988, 1996), is based on fieldwork carried out in the 1980's in four Minnesota restaurants. Yet, neither author is concerned with chefs and cooks working in 'haute cuisine' restaurants, and both their findings are now significantly dated. A little later on, a few studies focused their attention on the culture of chefs, among which are discussion papers on kitchen violence (Bloisi and Hoel, 2008; Johns and Menzel, 1999) and on the effects of chef occupational culture on hotel organisational culture (Cameron et al., 1999). Similarly, Pratten's (2003a, 2003b) papers on the retention and training of chefs and the qualities that make 'a great chef', respectively, are mainly conceptual and based on limited primary data. Meanwhile Lee Ross (1999) investigated the core job dimensions and motivating potential of chefs in 14 UK hospitals; he found that chefs using large scale-catering systems tended to be less engaged and motivated than those using traditional cook and serve operations.

With regards to more specific kitchen-related issues, a few authors have investigated the persisting lack of female chefs in professional kitchens (Banner, 1973; Cooper, 1998; Cooper, 2012; Fine, 1987; Swinbank, 2002). In addition, some insightful conceptual work has emerged on the effects of nouvelle cuisine on chef identity and culture (Wood, 1991; Rao et al., 2003) and on the trend for television and celebrity chefs (Ashley et al., 2004; Fattorini, 1994; Gillespie, 1994; Henderson, 2011; Wood, 2000;). Another stream of research investigates the skills and competencies required for chefs (i.e. Birdir and Pearson 2001; Hu 2010; Ko 2012; Robinson and Barron 2007; Zopiatis 2010); this body of research suggests that a balanced approach between operational, administrative and managerial/leadership competencies is needed.

Last but not least, a few European authors have focused their attention on the haute cuisine sector and on Michelin-starred chefs in particular, albeit from a management perspective. For example, while Balazs's $(2001,2002)$ main focus is on the leadership skills of French three-Michelin-starred chefs, Johnson et al. (2005) are interested in the management styles and motivations of two and threeMichelin-starred chefs in four European countries (Belgium, France, Switzerland and the UK) which they analyse in light of the operation and profitability of the selected establishments. Likewise, Surlemont et al.'s (2005) study details the revenue models of similarly graded Michelin-starred restaurants, whilst Surlemont and Johnson (2005) address the role of the Michelin-star rating system in preserving standards and chefs' creativity for the benefit of customers.

It is clear from this brief overview of the 'chef' literature that, although the body of knowledge about chefs has grown in recent years, the prevalence in the 'haute cuisine' sector and among Michelin-starred chefs of AOD use has not been studied, though as will be seen below, it has been alluded to in a few studies. 


\subsection{The role of occupational stress in $A O D$ use}

The literature shows a strong relationship between the occupational stress imposed by a chef's unique working environment and the consumption of alcohol and drugs. Indeed, in their study of two and three-Michelin-starred European chefs, Johnson et al. (2005) identify the high levels of stress and pressure associated with gaining a Michelin-star ranking, due to the need to consistently achieve high quality levels. In his depiction of the work environment of chefs and cooks, Fine (1988) highlights the extreme and unusual demands of the job, as do Murrey-Gibbons and Gibbons (2007) who found that the consumption of alcohol and smoking help chefs to cope with occupational stress caused by a physically demanding working environment. In an earlier study, Rowley and Purcell (2001) reported similar findings when they examined occupational stress and burnout within the hospitality industry in Northern Ireland. Chefs scored the highest levels of burnout amongst the occupational groups surveyed. The most common coping responses included an increased consumption of foods high in sugars, fats and caffeine, and AOD abuse. Fatigue, high emotional exhaustion and a low sense of personal achievement were characteristic in chefs' responses. More recently, Jung et al. (2012) found a strong link between occupational stress and turnover intention in the context of the Taiwanese luxury hotel industry. Kang et al. (2010) investigated the relationship between the work environment and certified chefs' burnout in the US; their findings interestingly suggest that a supportive work environment can on the one hand improve organisational commitment and on the other hand reduce burnout and intention to quit.

\subsection{The role of aggression in AOD use}

AOD use is also found to be correlated with high levels of aggression among chefs (Meloury and Signal, 2014). In their paper on kitchen violence, Johns and Menzel (1999) linked aggression with alcohol abuse in commercial kitchens. They suggested that the phenomenon was widespread within the UK hospitality industry. Indeed they argue that aggression and violence may be more widespread in kitchens than in any other workplace in the UK. They refer to kitchen violence as a mix of verbal and physical abuse, manifesting in physical and psychological impacts, including stress, strained relationships, alcoholism and heavy smoking. Chefs' violent and bullying behaviour was attributed to the physical pressures of the job, such as the heat, the noise from machines and shouting, and the drive to maintain standards of excellence. Kitchen violence has become deeply embedded in chefs' working culture (Alexander et al., 2012; Bloisi and Hoel, 2008; Burrow et al., 2015; Cooper, 2012; Midgley, 2005; Murray-Gibbons and Gibbons, 2007; Mathisen et al., 2011; Wood, 2000). Midgley (2005, p. 53) acknowledges the scope of the bullying problem in the industry and its likely consequences:

"Catering is a notoriously tough business with high stress levels. When bullying is stirred into the mix, disaster can be the result, even for those who consider themselves psychologically 
robust. One of the results of a military style of management in the kitchens is that catering is an industry riven by poor health and high levels of drug abuse and alcoholism".

Midgley (2005) reports drinking to be a common coping strategy, something deeply embedded in chefs' working culture. A recent study by Meloury and Signal (2014) similarly found a link between alcohol consumption and aggression among chefs in commercial kitchens in Australia. Male line cooks appear to be more aggressive than their supervisors (i.e. sous chef and head chef) because they are the backbone of the culinary industry, toiling in hot, cramped, fast-paced conditions to reach the head chefs high expectations' (p. 103). A similar portrait is painted by Pidd et al. (2014) who explored the extent of AOD abuse in trainee chefs in Australia and found high levels of alcohol and illicit drug use.

Interestingly, not all chefs endorse such attitudes to kitchen violence and mistreatment. For example, former Michelin-starred chef Prue Leith has accused Marco Pierre White and Gordon Ramsay of 'peddling macho nonsense and bullying staff to raise their profile' (Foggo, 2006, p. 10). It is perhaps significant that it is a female chef who acknowledges and challenges the brutal management techniques that tend to endorse and perpetuate kitchen violence. As noted earlier, women are still underrepresented in the realm of professional cooking and in the haute cuisine sector in particular.

\subsection{The role of occupational culture and deviance}

Given their unique working environment and their interdependency, chefs and cooks form a distinctive occupational community (Burrow et al., 2015; Cooper et al., 2017; Mac Con Iomaire, 2008). Indeed, Bourdain (2000, p.124), refers to chefs as a 'tribe'. Their unsocial working hours contribute to their exclusion from 'normal' social interaction and they enjoy a deep commitment to their colleagues, a 'blind, near-fanatical loyalty ... under battlefield conditions' (p.56). Bourdain also comments that a chef 'never shows up late, never calls in sick, and works through pain and injury' (p.55). In addition, communal links are reinforced by a kitchen brigade's interdependency and cooperation which generate a feeling of belongingness and community (Fine, 1996). The existence of an occupational community is reflected notably in chefs' and cooks' propensity to socialise at the workplace or to visit the workplace on a day off (Shamir, 1981).

Fine (1996, p. 126) argues that kitchen deviance in the form of drinking is an integral part of the occupational culture: "Much that goes on in the kitchen should not be reported to the management and must be hidden from customers....These deviant actions typically protect the organisation and the doing of work." Robinson's research (2008) corroborates this by identifying violence and AOD as the key elements of deviance in commercial kitchens. The occupational culture in this case appears to be linked directly with deviant practices such as drinking and drug use; Lee-Ross (2005) argues that this is a mechanism where the members of a given occupational group seek solidarity in their community in order to avoid 
stigmatisation. This contradicts the definition of employee deviance in the workplace, which is described by Robinson and Bennett (1995, p. 556) as "a voluntary behaviour that violates significant organisational norms and...threatens the well-being of an organisation, its members or both".

Pidd et al. (2014) discovered that young chefs are heavily influenced by workplace norms regarding AOD use. The socialisation process plays a pivotal role here whereby trainee chefs are exposed to their occupational culture, including accepted norms and behaviours such as alcohol consumption and drug use. Fine (1996) notes that bonds of communality and friendship are reinforced through play and humour, as well as through the collective consumption of alcohol at the end of a shift. This tendency is accommodated by the fact that alcohol is easily available in restaurant kitchens (Belhassen and Shani, 2012; Fine, 1996; Robinson, 2008). On the other hand according to Fine (1996, p. 130), the occupational community sets the boundaries in AOD use: "Drinking must be limited to permit the community to function. If it is, it is "no problem'; if not, the violator is tarred with the stigma of his deviance". Robinson (2008, p. 407) sees deviant behaviours in commercial kitchens as "a statement of occupational community". This view is consistent with Lee-Ross' (2005) argument that deviance practices are used as a boundary-forming exercise in delineating occupational membership.

From our discussion of the extant literature so far, there has been a strong indication of AOD use in commercial kitchens that is tolerated or even encouraged by this occupational group. The focus of our study is on AOD use in high end commercial kitchens and more specifically in Michelin-starred brigades in Great Britain and Ireland.

\section{Methodology}

Figueroa-Domecq et al. (2015) advocate the use of qualitative research to address sensitive research topics, and given that the exploration of AOD use among Michelin-starred chefs is potentially highly sensitive, the qualitative approach was deemed to be most appropriate. In-depth one-to-one semistructured interviews were used as they allowed participants to express themselves freely on a potentially sensitive topic. Rubin and Rubin (2011) note that the in-depth interview permits the exploration of differing perspectives, experiences and opinions.

Interviews were conducted over a 12-month period throughout Britain and Ireland with 54 Michelinstarred chefs. This represents approximately half of the total population. Participants' contact details were sourced from the Michelin Guide of Great Britain and Ireland (2011). Purposive sampling was used whereby the researcher uses their judgment to select cases to be included on the basis of their relevance to the research aim (Jones et al., 2013). The sample identified for the purposes of this study 
was the totality of Michelin-starred chefs and their kitchen 'brigades' in Britain and Ireland. A letter/email was sent to each chef explaining the research and asking for volunteers to agree to participate in an in-depth, face-to-face interview. A total of 86 invitations were sent out, and there was a positive response from 54 chefs, giving a $63 \%$ response rate. There was no apparent difference between responders and non-responders. Michelin-starred chefs are notorious for their hectic work schedules, therefore this can be seen as an impressive feat.

There is variation in the sample in terms of the location of the establishment (rural/urban), the type of establishment operated (hotel/restaurant), the number of Michelin stars held (1, 2 or 3), the chef's status as patron or employee, the chef's ethnicity, the size of the kitchen 'brigade' and its gender mix (see Table 1). There is a gender imbalance in the sample that is indicative of the under-representation of women among Michelin-star chefs. Interviews were conducted by one researcher at the participants' workplace, that is, in their natural setting; the length of each visit varied from half day to full day combined with overnight stay depending on the restaurant's location. The interviews varied in length, from 34 minutes to five hours and 37 minutes, with an average interview time of two hours and 57 minutes. With permission, all interviews were audio recorded.

Table 1: Participant profile (n: 54)

\begin{tabular}{|l|lr|l|l|l|}
\hline \multicolumn{2}{|l|}{ Nationality } & \multicolumn{2}{l|}{$\begin{array}{l}\text { Restaurant } \\
\text { Location }\end{array}$} & Gender & Employment Status \\
\hline British: 41 & American: 1 & England: 43 & Male: 50 & Head Chef \& Patron: 7 \\
Irish: 4 & Australian: & 2 & Wales: 1 & Female: 4 & Employee: 47 \\
French: 4 & Austrian: 1 & Scotland: 6 & & \\
& South African: 1 & Ireland: 4 & & \\
\hline
\end{tabular}

An interview guide was created, including the following topics: the type of AOD used; the reasons for its use; the place and frequency of use (in or out of workplace); the impact of AOD use on performance and well-being. The guide was designed to aid conversation but it was important that participants were encouraged to lead discussion (Charmaz, 2000); in this sense, the approach to interviews was flexible. This is particularly important in an exploratory study on a topic on which relatively little is known (Pidd et al., 2014). Thus each interview proceeded differently, depending on the bias of the interviewee. It was important that the interview felt like a conversation, that participants felt relaxed, in order to obtain good quality data (Morris, 2015). When the interviews drew to a close, almost all of the participants commented that they had enjoyed the conversation. For some chefs it was a cathartic process of personal reflection, clarification and re-evaluation, as it afforded the opportunity to discuss issues they had thought about, but seldom articulated. For others it raised 
questions that they had not otherwise considered and drew their attention to settings and relationships that they had usually taken for granted. In either case, many chefs appeared to appreciate the opportunity to talk about themselves and their experiences with an interested, supportive and sympathetic listener. As Mason (2000) observes, the in-depth interview often has a therapeutic quality for participants. For those who expressed a particular interest in the study, the researcher agreed to send them a copy of the findings for their perusal. Interviews were conducted until theoretical saturation was reached. This is defined by Charmaz (2000) as the point at which no major new insights are gained.

Ethical considerations were paramount, thus the project was approved by the Strathclyde Business School research ethics committee, and standard guidelines for ethical research were adhered to. Participants were assured that confidentiality and anonymity would be safeguarded; a participant information sheet and a consent form (including a confidentiality agreement) were provided. The names of chefs are replaced with numbers to protect anonymity. Finally, participants were assured of their right to withdraw from the project, including during the interview itself.

Thematic analysis was adopted to analyse the qualitative data. This involved the processes of familiarisation, transcription, coding and categorising (Braun and Clarke, 2006). Firstly the interviews were transcribed verbatim, read and re-read several times to note initial ideas. Researcher observations and impressions recorded during the interview were also reviewed. These 'memos' were subsequently written in the margins of the relevant transcripts alongside the accompanying data to which they refer, thus aiding analysis. A decision was made early on not to use a specialised software, such as NVivo, but to use manual analysis, whereby the researcher is closer and more intimately involved with the data (Jones et al. 2013). Using an inductive approach, the transcripts were coded. This process only begins after the familiarisation stage has taken place (Jones et al. 2013). A code is an identifying name or label given to a data unit. It is a word used to represent a phenomenon the researcher notices in the text. It must be distinct so that it is obviously different from another code, and there must be a low level of inference; it must be close to concrete description. Therefore, in this study, a discrete label was created to denote and differentiate meaning in the text. A mass of codes was eventually formed, which led to the process of categorisation, whereby codes were clustered according to relevance into discrete categories, or themes (Grbich, 2007). The final stage of analysis consisted of interpretation of the data, which involved reflection on meaning and a dialogue with the relevant literature in order to aid illumination of the data. As the following section reflects, analysis generated three distinct themes: alcohol and occupational culture; using AOD to 'come down'; using AOD to 'keep going'. The themes are illustrated with quotations from the participants, which lends authenticity and trustworthiness to the research report (Jones et al. 2013). 


\section{Findings and Discussion}

\section{1. 'It's a way of life': Alcohol as part of the occupational culture}

The chefs interviewed traced the tendency towards alcohol use to days when they were freely given alcohol in the kitchen. These were referred to as 'sweat pints' in the trade, consumed to help keep chefs going during a hot and stifling service. The tradition, though discontinued, has led to alcohol consumption being a deeply ingrained norm of behaviour, as expressed by Chef 29 :

“30, 35 years ago, they actually gave the cooks 'sweat pints', which was like suicide. You got people working in an environment, they're sweating, needing liquid and you're giving them beer. There was no common sense, it was just, 'ah, just give them beer, they'll be happy.',

Participants stated that drinking culture has long existed, not only at the lower end of the catering industry but also in high profile hotels and restaurants. Alcohol is used to motivate chefs to work longer and to endure the harsh kitchen environment:

"Alcohol has always been in the kitchens. When I started off, you were given a couple of bottles of beer every day. That's what you were entitled to. It was normal. I remember when I was at Anonymous, for example, there were 80, 90 chefs there. If some chefs didn't like the beer, didn't want it, they traded it for something else, so somebody could end up with 10 or 15 bottles! And of course, there would be trouble. I've also seen where the head chef used to hand out bottles of vodka in the morning just to keep chefs happy." (Chef 34)

Furthermore, it was commonplace for chefs to go to the pub in the afternoons during their split shifts and drink alcohol. Unsurprisingly perhaps, being under the influence of alcohol, some chefs later became violent and abusive:

"There's naturally aggression there anyway. You put beer on top of that, sharp knives, fryers, ovens, hot utensils, you're asking for trouble. That also brought this image of off-their-head chefs. I've seen it. Forget the kitchen, put somebody in a sauna, give them four pints of lager, and let them out of the sauna and see what you get." (Chef 29)

Though the practice of giving chefs alcohol in the kitchen is discontinued, the years of alcohol use has had a long-term effect on chefs' health and in some cases has led to addiction, as the following participants testify:

"Every afternoon, I would go and read the paper in the pub and have a Coke and the boys would drink three or four pints of Stella, and then go back to work. Two of them were alcoholics. One was the head chef that was an alcoholic. And the other one was someone who would drink a bottle of gin a day he had in his fridge that no-one knew about apart from me." (Chef 3)

'I'm a functioning alcoholic. I won't drink before seven o'clock at night, but I'll hoof down a bottle of wine every night before I go to bed-easy. I think because it was part of the culture, your body and your brain thinks that's the only way you're going to get to sleep tonight. You've had a hard day, and it numbs the pain." (Chef 14) 
Drinking alcohol after a shift was and is commonly felt to be a way to recover from occupational stress. However, as the above excerpts reveal, this cultural norm among chefs carries serious longterm consequences for mental and physical health. The legacy of prolonged alcohol use is acknowledged by many of the participants.

\subsection{Coming down from the 'buzz' of service}

This study shows that the fast paced, high energy environment in which chefs work has implications for AOD use in terms of recovering equilibrium following a busy service. Participants used a military analogy to describe going into service; it was likened to 'preparing to go into battle' owing to the feelings of fear, anxiety and nervousness experienced by members of the kitchen brigade on a twice daily basis. Chef 35 makes the point:

'Adrenalin gets you through it, and that's why you get so hyper. You've got like a nervous feeling inside - not nervous, but like excitement, a nervous feeling in your stomach, like a butterfly kind of feeling'.

This is reinforced by Chef 19:

"I get nervous every service. I'm anxious as well to get it right, and I'm nervous. And I think if I ever lost that, that's the day I'd give up. Because I think that gives you an edge to sort of doing the service and stuff. And I think to a certain extent it's what keeps you going. It's a mixture of anxious and nervous."

It is apposite in a study on AOD use to observe that the vocabulary used to describe adrenalinefuelled working states (the 'buzz', the 'rush', the 'high') common to a busy service mirrors that used to refer to intoxication. Chef 28 alludes to the extreme euphoric state that is experienced during service:

"It's almost like a great big white light, everything is $f^{* * * * * g}$ amazing. Those moments are total achievement; those moments are the total buzz".

Chef 40 makes a direct comparison between service and drugs:

"It's more than a drug. There's nothing better than that feeling of being on the stove, when you're in the $f^{* * * * *} g$ shit, but you know you're in control".

The question then arises: what do chefs do to 'come down' from such a high? Chef 8 provides the answer:

'You're going through service and the buzz, or drug, if you like, and then there's the other side of it, coming off that buzz, off that drug - a natural drug. I say, I couldn't half murder a pint. Oh, God, I need to go down the pub for a pint. It's just a release really."

According to Chef 25, alcohol offers both calm and comfort:

"You can be really buzzing after a service or worse still, if you had a bad service, then you'll have a drink like to calm you down, or stop you feeling mopey". 
Chef 24 identifies a time span for regaining composure:

"It takes two or three hours to come down because you're on a high. You need time; you can't just switch off just like that. You need time, really, to come down."

Without the release or comfort provided by alcohol, sleep is elusive:

"We wind ourselves up for that buzz of the service, and when it's all over, we're physically finished, mentally drained. We might be so hyper that we need to go and get a few lagers down us. Ask anyone in that kitchen there can he leave Saturday night's service, go home and go to bed? He can't. He needs an hour or two hours to come down, with or without wine, with or without drink, with or without anything, but to calm down to go to sleep." (Chef 28)

This study is not alone in drawing attention to the atypical nature of a chef's unsociable working hours, combined with the high adrenaline and physically and mentally demanding nature of their work. However this study goes further in suggesting that chefs have a need for coping mechanisms not commonly seen in many other occupations, which makes them susceptible to AOD use, and which can have long term implications for health and well-being. A recent study by Roche et al. (2014) on trainee chefs coping mechanisms came to similar conclusions. The coping process has been defined in many ways, yet the dominant model accepted in the psychology literature is the transactional coping process (Kristiansen and Roberts 2010). According to Holt et al. (2005), this is classed as a process of transaction between the individual and the environment: coping represents efforts to manage the demands that an individual appraises as taxing or exceeding his or her resources. When situations are appraised as challenging, threatening or harmful, coping responses are required (Holt et al., 2007).

Chefs are no longer allowed to drink alcohol in the kitchen during service, nor do they commonly drink alcohol during their split shifts, however, there is still a certain shared drinking culture prevalent amongst chefs when they socialise and unwind after a shift. There is a propensity towards using alcohol to self-medicate, as a vehicle for relieving the stresses and strains that accompany their long and arduous shifts and for restoring balance. Such drinking practices also constitute a bonding mechanism that offers a sense of togetherness. In the words of Chef 23 '...it's long, hard hours. Everyone works hard, everyone plays hard'. This study observes a normalisation of drinking to unwind. Even if this practice is detrimental to health, it is the coping mechanism used by chefs to deal with the stresses associated with the high end kitchen environment.

\subsection{Using drugs to come down and to keep going}

According to the chefs interviewed, the use of drugs is now far more prevalent in today's kitchens. Chef 8 referred to the common use of marijuana to help recovery from a stressful shift: 
"You see pot use and stuff like that; you see a lot of that, a lot of people in the industry smoke pot. You've worked hard, you can't go to sleep. You want to socialise, and you want to talk to people about day-to-day things, rather than talk about work. You just want to totally switch off, so that's why people have a joint."

The above excerpt shows that marijuana is used, like alcohol, as an aid to sleep and as a means to switch off. The use of stimulants as a pick-me-up when chefs are physically exhausted and mentally drained was also reported. Chef 8 also refers to drugs as a means to maintain performance at the requisite level, most notably during the intense pressure of a busy service:

"It just gets you through it really, the physical work - it's not to enjoy yourself - just to keep yourself going. I've seen quite a lot of amphetamine use, just to keep you awake, and to keep you at the pace you need to work."

Chef 19 similarly notes that 'the drugs get you back up again'. The drugs referred to most commonly are cocaine and amphetamines (widely known as 'speed') that are associated with offering an energy boost. Alarmingly, Chef 2 recalls being told: 'If I were to take speed, I'd be a damned sight better cook than I was. I was openly encouraged to take it'. Chef 34 further elaborates and points to a culture of drug use:

"In the last ten years, there are certain kitchens where openly they take drugs; some kitchens where they have actually been given drugs in order to get them on a high. There's much less alcohol now in the kitchen than there used to be, but drugs I think is a different matter.

Chef 44 is more damning in his judgement on how widespread drug use is:

"Drugs and alcohol are completely abused in this trade. Drug abuse is rife in a lot of places, but I think more so now as you're getting to the top end, because this business is becoming so competitive, you just can 't carry on if you don't do drugs."

This study points to the normalisation of drug use in the high end kitchen brigades. It is apparent that a number of chefs accept or tolerate substance use as a means to stabilise or enhance job performance, due to high professional standards and competition. This finding is consistent with the work of Kitterlin and Erdem (2009) who following interviews with ten US based chefs suggested that the use of illicit drugs in commercial kitchens is not necessary negative since they maintain or enhance performance. Such a conclusion clearly overlooks the longer term health implications of this trend towards increasing drug use. This is a 'whatever it takes' attitude that overlooks the well-being of chefs, placing operational excellence above the individual. Foucault's (1977) description of normalisation comes from his understanding of how the military and penitentiary system gain control of individuals, but it can be used to understand the drug culture within kitchens.

\section{Conclusion}

This study reveals that alcohol consumption is ingrained in the occupational culture of Michelin-starred chefs; this may well be traced back to the days when historically chefs were freely given alcohol in the 
kitchen. It was common practice for chefs to go to the pub and drink alcohol during their split shifts. Though such drinking practices no longer exist in today's high-end commercial kitchens, this study identifies that there is still a shared drinking culture amongst chefs, with alcohol being used to help them to socialise and to cope with the highly pressurised and stressful nature of their job. Alcohol is also used to regain balance following the 'rush' of a busy service (as is marijuana, increasingly). Alcohol is revealed to act as a group bonding mechanism with its consumption being normalised among chefs despite the negative health legacy of prolonged and sustained alcohol use. The findings also suggest that AOD use and its tolerance among brigade members differentiates chefs as an occupational group in their work settings (i.e. hotels and restaurants). This is consistent with Robinson's view (2008, p. 407) that deviant behaviours in commercial kitchens represent "a statement of occupational community".

This study also highlights the use of drugs, specifically cocaine and amphetamines, as a way to maintain performance. The tolerance and indeed encouragement of drug use in the professional kitchen reveals a perhaps shocking subordination of the well-being of the chef to the needs of the restaurant. Performance must be maintained at all costs: the end justifies the means. This can be said to represent exploitation of the chef whose health is subordinated to the needs of the 'business'. The chef's own desire for and drive towards excellence makes him/her susceptible to such maltreatment. This study therefore reveals that AOD use has a dual function, both related to the nature of a chef's work. It acts as a vehicle for achieving calm after a busy service and as a means to maintain or enhance performance during service. This understanding has management and theoretical implications.

\subsection{Theoretical and Managerial implications}

This study contributes to a small but gradually increasing literature on AOD use at work and focuses specifically on its use Michelin-starred chefs. This is the first study conducted in the context of Michelinstarred restaurants and it therefore provides useful insights into the relationship between occupational culture, job characteristics and AOD use. The theoretical contribution made by this study lies in the association between AOD use among Michelin-starred chefs and service: it aids and enhances performance during service and permits return to equilibrium following a busy service. Benton (2009) refers to "high functioning alcoholics" (HFA), and this study suggests that this term has relevance for this study, in terms of the use of AOD among high functioning Michelin-starred chefs. A high-functioning alcoholic (HFA) is clinically defined as someone who is able to maintain their 'outside life' - such as a job, a home, a family and friendships, all while drinking to excess (Sharp, 2009). Many HFAs are not viewed by society as being alcoholic because they are successful in their career and personal life. These achievements often lead HFAs to deny that they have a problem; they are less likely to feel they need treatment for alcoholism, and may slide through the cracks in the healthcare system because they are not diagnosed. Though the focus of this study is on Michelin-starred chefs, there are clearly other highly 
pressurised environments where professionals use AOD to cope and to maintain or enhance performance (Belhassen and Shani, 2012; Murray-Gibbons and Gibbons, 2007; Roche et al., 2015).

In terms of managerial implications, it is argued that the tolerance of drug use in the professional kitchen may be detrimental to organisational efficiency. Alcohol and drug use in commercial kitchens can lead to low productivity, absenteeism, high turnover, and bullying. There are also health implications to prolonged AOD use for chefs. Particularly in the higher end of the profession, many chefs experience burn-out or alcohol / drug addiction due to the highly stressful working environment. Although there are signs of change, especially in the large multinational and national chains, this study shows that the problem persists. An improvement in the work-life balance of the chef would trigger several positive changes such as increased productivity, lower staff turnover and a reduced proclivity towards substance abuse.

This study indicates a clear role for a Michelin-starred restaurant's HR department or for its senior management in terms of creating and implementing prevention strategies. A clear message should be sent to head chefs and their brigades that AOD use will not be tolerated before, during or after service. The use of random drug testing among brigade members would reinforce this message (this is already common practice in the US). The involvement of Chefs' Associations and awarding bodies (i.e. the Michelin Guide) would also be valuable in terms of underlining the importance of AOD use prevention strategies. These stakeholders could lead awareness campaigns and contribute to the creation of national / international standards in terms of AOD use in commercial kitchens. Educating the younger generations of chefs is key to sustained change: the professionalization of the occupation and the fact that the majority of young chefs now receive some kind of education (vocational or tertiary) may help towards the eradication of the phenomenon of alcohol and drug abuse in Michelin-starred kitchens. A new-found level of professionalism at the high-end of professional cooking, coupled with an elevation in the status and standing of chefs may subvert the tendency towards alcohol and drug use, but this remains to be seen. The chef is now more visible, and for this reason, s/he may be inclined to shed the negative practices that have been for so long a part of the culture of the professional kitchen.

\subsection{Limitations and future research}

This study focuses on Michelin-starred chefs only: thus future research on AOD use should extend study to other categories of cooking professionals (i.e. in fast food, mid-range restaurants, contract catering companies etc.), as different working environments encourage the creation of sub-cultures hence different attitudes towards AOD use. Such research would test the transferability of the findings produced by this research. This study also focuses on a specific cultural context (Britain and Ireland). Further studies are needed in different cultural contexts; it is well documented in the literature (i.e. 
Cooper, 2012; Pizam, 2016; Zopiatis, 2010) that chefs in different countries develop a distinct occupational identity and work ethos.

\section{References}

Alexander, M., MacLaren, A., O'Gorman, K., and Taheri, B., (2012). 'He just didn't seem to understand the banter': Bullying or simply establishing social cohesion? Tourism Management, 33(5), $1245-1255$.

Anderson, K.N. (1998). Mosby's medical, nursing and allied health dictionary. $5^{\text {th }}$ ed., St. Louis (MO), C.V.Mosby.

Ashley, B., Hollows, J., Jones, S. and Taylor, B. (2004). Food and Cultural Studies. London: Routledge.

Balazs, K. (2001). 'Some like it haute': Leadership lessons from France's great chefs. Organisational Dynamics, 30(2): 134-48.

Balazs, K. (2002). Take one entrepreneur: The recipe for success of France's great chefs. European Management Journal, 20(3), 247-59.

Banner, L.W. (1973). Why women have not been great chefs. South Atlantic Quarterly, 72(2), 193212.

Belhassen, Y., and Shani, A. (2012). Hotel workers' substance use and abuse. International Journal of Hospitality Management, 31(4), 1292-1302.

Benton, S.A. (2009). Understanding the high-functioning alcoholic: Professional views and personal insights. Westport (CT): Greenwood Publishing Group.

Birdir, K., and Pearson, T. E. (2000). Research chefs' competencies: a Delphi approach. International Journal of Contemporary Hospitality Management, 12(3), 205-209.

Bloisi, W., and Hoel, H. (2008). Abusive work practices and bullying among chefs: A review of the literature. International Journal of Hospitality Management, 27(4), 649-656.

Bourdain, A. (2000). Kitchen Confidential: Adventures in the Culinary Underbelly. London: Bloomsbury.

Bourdain, A. (2010). Medium Raw: A Bloody Valentine to the World of Food and the People Who Cook. London: Bloomsbury.

Bowey, A.M. (1976). The Sociology of Organisations. London: Hodder and Stoughton.

Braun, V. and Clarke, V. (2006). Using thematic analysis in psychology. Qualitative research in psychology, 3(2), 77-101.

Burrow, R., Smith, J. and Yakinthou, C. (2015). 'Yes Chef': life at the vanguard of culinary excellence. Work, Employment \& Society, 0950017014563103. 
Cameron, D.S., Gore, J., Desombre, T. and Riley, M.J. (1999). An examination of the reciprocal affects of occupation culture and organisation culture: The case of chefs in hotels. International Journal of Hospitality Management, 18(3), 225-34.

Charmaz, K. (2000). Grounded theory: Objectivist and constructivist methods. In Denzin, N.K. and Lincoln, Y.S. (eds.). Handbook of Qualitative Research, 2nd edn. (509-535). Thousand Oaks: Sage Publications.

Chelminski, R. (2006). The Perfectionist: Life and Death in Haute Cuisine. London: Penguin Books.

Chivers, T.S. (1972). Chefs and cooks: A study in the sociology of occupations. Unpublished Ph.D. thesis, University of London.

Chivers, T.S. (1973). The proletarianisation of a service worker. Sociological Review, 21, 633-56.

Cooper, A. (1998). "A Woman's Place is in the Kitchen”: The Evolution of Women Chefs. New York: Van Nostrand Reinhold.

Cooper, J. (2012). The occupational identity and culture of chefs in United Kingdom (UK) haute cuisine restaurants. Unpublished Ph.D. thesis, University of Strathclyde.

Cooper, J., Giousmpasoglou, C. and Marinakou, E. (2017). Occupational identity and culture: the case of Michelin-starred chefs. International Journal of Contemporary Hospitality Management, 29(5). DOI: 10.1108/IJCHM-02-2016-0071

Fattorini, J. (1994). Food journalism: A medium for conflict? British Food Journal, 96(10), 24-28.

Ferguson, P.P. and Zukin, S. (1998). The careers of chefs. In Scapp, R. and Seitz, B. (eds.), Eating Culture (92-111). Albany (NY): State University of New York Press.

Figueroa-Domecq, C., Pritchard, A., Segovia-Pérez, M., Morgan, N., and Villacé-Molinero, T. (2015). Tourism gender research: A critical accounting. Annals of Tourism Research, 52, 87-103.

Fine, G.A. (1987). One of the boys: Women in male-dominated settings. In Jones, M.O., Moore, M.D. and Snyder, R.C. (eds.), Inside Organisations: Understanding the Human Dimension (503-51). Cheltenham, Edward Elgar.

Fine, G.A. (1988). Letting off steam? Redefining a restaurant's work environment. In Kimmel, M.S. (ed.). Changing Men: New Directions in Research on Men and Masculinity (131-147). London: Sage Publications.

Fine, G.A. (1996). Kitchens: The Culture of Restaurant Work. Berkeley (CA): University of California Press.

Foggo, D. (2006). Leith seethes at Ramsay bad-boy gravy train. The Sunday Times, 22 October, 10.

Foucault, M. (1977). Discipline and punish the birth of the prison. London: Penguin Books.

Gillespie, C.H. (1994). Gastrosophy and nouvelle cuisine: Entrepreneurial fashion and fiction. British Food Journal, 96(10), 19-23.

Goffman, E. (1959). The Presentation of Self in Everyday Life. Garden City (NY): Doubleday.

Grbich, C. (2007). Qualitative data analysis: An introduction. Thousand Oaks: Sage Publications. 
Guyette, W.C. (1981). The executive chef: Manager or culinarian. Cornell Hotel and Restaurant Administration Quarterly, 22(3), 71-78.

Holt, N.L., Berg, K.J. and Tamminen, K. (2007). Tales of the unexpected: Coping among female collegiate volleyball players. Research Quarterly for Exercise and Sport, 78, 117-132.

Holt, N.L., Hoar, S.D. and Fraser, S.N. (2005). How does coping change with development? A review of childhood adolescent sport coping research. European Journal of Sport Science, 5, 25-39.

Hu, M. L. M. (2010). Developing a core competency model of innovative culinary development. International Journal of Hospitality Management, 29(4), 582-590.

Jackson, K. M. and Sartor, C. E. (2016). The natural course of substance use and dependence. In Sher, K. (Ed.). The Oxford handbook of substance use and substance use disorders (67-132). Vol.1, Oxford: Oxford University Press.

Johns, N. and Menzel, P.J. (1999). If you can't stand the heat: kitchen violence and culinary art. International Journal of Hospitality Management, 18(2), 99-109.

Jones, I., Brown, L. and Holloway, I. (2013). Qualitative research in sport and physical activity. London: SAGE.

Johnson, C., Surlemont, B., Nicod, P. and Revaz, F. (2005). Behind the stars: A concise typology of Michelin restaurants in Europe. Cornell Hotel and Restaurant Administration Quarterly, 46(2), 170187.

Jung, H. S., Yoon, H. H., and Kim, Y. J. (2012). Effects of culinary employees' role stress on burnout and turnover intention in hotel industry: moderating effects on employees' tenure. The Service Industries Journal, 32(13), 2145-2165.

Kang, B., Twigg, N. W., and Hertzman, J. (2010). An examination of social support and social identity factors and their relationship to certified chefs' burnout. International Journal of Hospitality Management, 29(1), 168-176.

Kitterlin, M. and Erdem, M. (2009). A qualitative assessment of employee attitudes towards preemployment drug-testing in the full-service restaurant industry. Consortium Journal of Hospitality \& Tourism, 14(1), 5-21.

Ko, W. H. (2012). The relationships among professional competence, job satisfaction and career development confidence for chefs in Taiwan. International Journal of Hospitality Management, 31(3), 1004-1011.

Kristiansen, E. and Roberts, G.C. (2010). Young elite athletes and social support: Coping with competitive and organizational stress in "Olympic" competition. Scandinavian Journal of Medicine and Science in Sports, 20, 686-695.

Lee-Ross, D. (1999). A comparative survey of job characteristics among chefs using large and smallscale hospital catering systems in the UK. Journal of Management Development, 18(4), 342-350.

Lee-Ross, D. (2005). Organisational culture and occupational communities: A preliminary international study of pan-industry dimensions in hotels. In: proceedings CAUTHE Conference: Sharing Tourism Knowledge, Alice Springs, pp.1-10. 
Mac Con Iomaire, M. (2008). Understanding the heat - mentoring: A model for nurturing culinary talent. Journal of Culinary Science \& Technology, 6(1), 43-62.

Mason, J. (1996). Qualitative Researching. London: Sage Publications.

Mathisen, G.E., Einarsen, S., and Mykletun, R. (2011). The relationship between supervisor personality, supervisors' perceived stress and workplace bullying. Journal of Business Ethics, 99(4), 637-651.

Meloury, J., and Signal, T. (2014). 'When the plate is full': Aggression among chefs. International Journal of Hospitality Management, 41, 97-103.

Michelin Guide, The. (2011). Great Britain \& Ireland 2011. Michelin Travel Publications, Watford.

Midgley, D. (2005). Stay cool in the kitchen. Management Today, September, 50-57.

Morris, A. (2015). A practical introduction to in-depth interviewing. Thousand Oaks: Sage Publications.

Murray-Gibbons, R. and Gibbons, C. (2007). Occupational Stress in the chef profession. International Journal of Contemporary Hospitality Management, 19(1), 32-42.

Ottenbacher, M. and Harrington, R. J. (2007). The innovation development process of Michelinstarred chefs. International Journal of Contemporary Hospitality Management, 19(6), 444-460.

Page, E.B. and Kingsford, P.W. (1971). The Master Chefs: A History of Haute Cuisine. London: Edward Arnold.

Palmer, C., Cooper, J. and Burns, P. (2010). Culture, identity, and belonging in the 'culinary underbelly'. International Journal of Culture, Tourism and Hospitality Research. 4(4), 311-326.

Peterson, Y. and Birg, L.D. (1988). Top hat: The chef as creative occupation. Free Inquiry in Creative Sociology, 16(1), 67-72.

Pidd, K., Roche, A. and Kostadinov, V. (2014). Trainee chefs' experiences of alcohol, tobacco and drug use. Journal of Hospitality and Tourism Management. 21, 108-115.

Pizam, A. (2010). Alcoholism among hospitality employees. International Journal of Hospitality Management, 29, 547-548.

Pizam, A. (2016). The changing social status of chefs. International Journal of Hospitality Management, 59, 116-117.

Pratten, J.D. (2003a). The training and retention of chefs. International Journal of Contemporary Hospitality Management, 15(4), 237-242.

Pratten, J.D. (2003b). What makes a great chef? British Food Journal, 105(7), 454-459.

Ramsay, G. (2006). Humble Pie. London: HarperCollins.

Rao, H., Monin, P. and Durand, R. (2003). Institutional change in toque ville: Nouvelle cuisine as an identity movement in French gastronomy. The American Journal of Sociology, 108(4), 795-843.

Robinson, R. N. (2008). Revisiting hospitality's marginal worker thesis: A mono-occupational perspective. International Journal of Hospitality Management, 27(3), 403-413. 
Robinson, R. N., and Barron, P. E. (2007). Developing a framework for understanding the impact of deskilling and standardisation on the turnover and attrition of chefs. International Journal of Hospitality Management, 26(4), 913-926.

Robinson, R. N., Solnet, D. J., and Breakey, N. (2014). A phenomenological approach to hospitality management research: Chefs' occupational commitment. International Journal of Hospitality Management, 43, 65-75.

Roche, A. M., Pidd, K. and Kostadinov, V. (2014). Trainee chefs' experiences of stress, bullying and coping in commercial kitchens. Journal of Health, Safety and Environment, 30(2), 259-269.

Roche, A. M., Lee, N. K., Battams, S., Fischer, J. A., Cameron, J., and McEntee, A. (2015). Alcohol use among workers in male-dominated industries: A systematic review of risk factors. Safety science, 78, 124141.

Rowley, G. and Purcell, K. (2001). As cooks go, she went: is labour churn inevitable? Hospitality Management, 20: 163-85.

Rubin, H.J., and Rubin, I.S. (2011). Qualitative interviewing: The art of hearing data. Thousand Oaks, Sage Publications.

Saunders, K.C. (1981a). Social Stigma of Occupations: The Lower Grade Worker in Service Organisations. Farnborough, Gower.

Saunders, K.C. (1981b). The influence of the menu structure on social relations in the kitchen. Hospitality, June, 14-18.

Shamir, B. (1981). The workplace as a community: The case of British hotels. Industrial Relations Journal, 12(6), 45-56.

Sharp, R. (2009). Working hard drinking harder. http://www.independent.co.uk/life-style/health-andfamilies/features/working-hard-drinking-harder-1763130.html (retrieved 26/10/2017).

Stierand, M.B. and Dörfler, V. (2012). Reflecting on a phenomenological study of creativity and innovation in haute cuisine. International Journal of Contemporary Hospitality Management, 24(6), 946-957.

Surlemont, B. and Johnson, C. (2005). The role of guides in artistic industries: The special case of the 'star system' in the haute-cuisine sector. Managing Service Quality, 15(6), 577-590.

Surlemont, B., Chantrain, D. Nlemvo, F. and Johnson, C. (2005). Revenue models in haute cuisine: An exploratory analysis. International Journal of Contemporary Hospitality Management, 17(4/5), 286-301.

Swinbank, V.A. (2002). The sexual politics of cooking: A feminist analysis of culinary hierarchy in western culture. Journal of Historical Sociology, 15(4), 464-494.

White, M.P. (1990). White Heat. London: Mitchell Beazley.

Wood, R.C. (1991). The shock of the new: A sociology of nouvelle cuisine. Journal of Consumer Studies and Home Economics, 15(4), 327-338. 
Wood, R.C. (2000). Why are there so many celebrity chefs and cooks (and do we need them)? Culinary criticism and crassness on television and beyond. In Wood, R.C. (ed.), Strategic Questions in Food and Beverage Management (129-152). Oxford: Butterworth-Heinemann. 